\title{
Uma análise crítica de algumas decisões proferidas pelo STF, STJ e TRF da 4a região no que diz respeito ao critério temporal do imposto de importação
}

\author{
Bruna Carolina Tâmega ${ }^{1}$
}

\begin{abstract}
Resumo
Este artigo versa sobre a regra matriz do imposto de importação: hipótese tributária (critério material, temporal e espacial) e relação jurídica tributária (critério pessoal - sujeito ativo e passivo - e critério quantitativo - base de cálculo vezes alíquota). Outrossim, discorre sobre alguns julgados proferidos pelo Supremo Tribunal Federal (STF), Superior Tribunal de Justiça (STJ) e Tribunal Regional Federal (TRF) da 4a Região, no que diz respeito ao critério temporal do imposto em questão.
\end{abstract}

Palavras-Chave: Imposto de importação; Entrada no território nacional; Registro da declaração de importação.

\section{Introdução}

O imposto de importação encontra-se disciplinado no artigo 153 da Constituição Federal, nos artigos 19 a 22 do Código Tributário Nacional (CTN) e em diversas legislações infraconstitucionais esparsas, dentre as quais o Decreto-Lei no 37/66, que, além de dispor sobre o imposto de importação, reorganiza os serviços aduaneiros e dá outras providências.

O fim precípuo desse imposto, também conhecido por tarifa aduaneira, direitos de importação, tarifas das Alfândegas, direitos aduaneiros, dentre outras denominações, é proteger e incentivar a aplicação de capitais nas indústrias nacionais. Tem natureza regulatória porque objetiva regular o comércio exterior mais do que arrecadar recursos financeiros. Daí porque se fala mais em função extrafiscal do que arrecadadora. Com efeito, Hugo de Brito Machado (2006, p. 317) leciona que o imposto de importação “é muito mais importante como instrumento de proteção da indústria nacional do que como instrumento de arrecadação de recursos financeiros para o tesouro puro".

Por isso, o imposto de importação é livre do princípio da anterioridade e não precisa

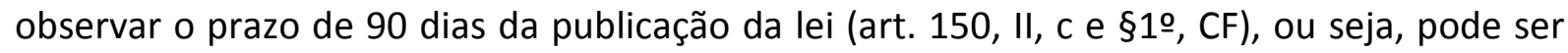

1 Formanda em Direito pela Universidade Estadual de Londrina, e-mail bru_tamega@yahoo.com. 
cobrado no mesmo exercício em que seja publicada lei que o instituir ou aumentar, a partir do momento de sua vigência. Além disso, é facultado ao Poder Executivo alterar a alíquota do imposto de importação (art. 153, § 1으, CF) por meio de Decreto - Leis que carece de agilidade nas reformulações legislativas.

Dentro desse contexto, o presente artigo, além de discorrer sobre os elementos que compõem a regra matriz do imposto de importação - hipótese tributária (critério material, espacial e temporal) e relação jurídica tributária (critério pessoal e quantitativo) - tem por objetivo principal analisar algumas decisões proferidas pelo Supremo Tribunal Federal, Superior Tribunal de Justiça e Tribunal Regional Federal da 4a Região (que engloba os Estados do Rio Grande do Sul, Santa Catarina e Paraná) no que diz respeito ao critério temporal do imposto de importação.

\section{Hipótese tributária do imposto de importação}

O artigo 19 do Código Tributário Nacional estabelece o fato gerador do imposto de importação, qual seja, a entrada do produto estrangeiro no território nacional. O imposto de importação grava, portanto, a introdução no território nacional de produtos estrangeiros, considerados estes como qualquer bem material procedente de outro país e dotado de valor econômico.

O critério material consiste em importar, trazer do exterior, fazer vir de outro país produto estrangeiro ou desnacionalizado (aquele que perdeu a característica de nacional ao ser exportado) destinado a permanecer definitivamente no Brasil uma vez que não incide imposto de importação, conforme preceitua o Decreto-Lei no $37 / 66$, sobre mercadorias que apenas fazem escala no Brasil por embarcação ou aeronave ou mercadorias estrangeiras que ingressam no território nacional tão somente para participar de feiras ou exposições, retornando à origem após cumprida sua finalidade. Afora isso, o Decreto no 2.412/97 permite a importação, com suspensão do pagamento de tributos, de mercadorias que serão submetidas à industrialização e, em seguida, destinadas à exportação.

O critério espacial é o território nacional, entendido como todo o espaço em que o Brasil exerce sua soberania nacional. A Lei $n$ o $8.617 / 93$ dispõe sobre os componentes do território nacional, a saber: mar territorial (faixa de 12 milhas marítimas medidas a partir da linha de base da costa continental em maré baixa); zona contígua (faixa adjacente ao mar 
territorial, de igual largura); zona econômica exclusiva (faixa que se estende das 12 às 200 milhas marítimas) e plataforma continental (leito e o subsolo das áreas submarinas que se estendem além do mar territorial até 200 milhas marítimas da linha de base).

No entanto, é só até o fim da zona contígua que o Brasil pode tomar medidas de fiscalização para evitar infrações aos regulamentos aduaneiros (art. 5ㅇ, I, Lei no 8.671/93). O critério espacial abrange, portanto, todo o território nacional até as 24 milhas marítimas contadas da linha de base da costa continental em maré baixa, excluído, entretanto, o território brasileiro abarcado por zonas francas, onde não há incidência do imposto de importação nem habitual controle aduaneiro.

Já o critério temporal é a data da entrada da mercadoria ou produto no território nacional, nos termos dos artigos 19 do CTN e 1을 do Decreto-Lei no 37/66. Contudo, os artigos 23 e 44 do Decreto-Lei no 37/66 estabelecem que, em se tratando de mercadoria despachada para consumo, considera-se como ocorrido o fato gerador na data do registro, na repartição aduaneira competente, da declaração feita para o desembaraço da mercadoria. Esse ponto vai ser analisado mais a frente.

\section{Relação jurídica tributária}

No que atine ao critério pessoal, o sujeito ativo, ente competente para instituir, fiscalizar, exigir/cobrar e arrecadar o imposto de importação é a União (art. 153, CF). O sujeito passivo pode ser o contribuinte (aquele tem relação pessoal e direta com o fato gerador) ou o responsável (aquele que não pratica o fato gerador, mas é responsável pelo cumprimento da obrigação tributária).

Preceitua o artigo 22 do CTN que contribuinte do imposto de importação é o importador ou quem a ele a lei equiparar e o arrematante de produtos apreendidos ou abandonados. O art. 31 do Decreto Lei 37/66 arrola como contribuinte o importador e os equiparados a ele: o destinatário de remessa postal internacional indicado pelo respectivo remetente e o adquirente de mercadoria entrepostada.

Considera-se importador qualquer pessoa que promova a entrada de mercadoria estrangeira no Território Nacional. Pode estar regularmente estabelecida ou não, pois a capacidade tributária passiva independe de formalismos (art.126 CTN). O destinatário de remessa postal internacional indicado pelo respectivo remetente é sujeito passivo da relação 
jurídica tributária sempre que a encomenda revele destinação comercial ou exceda o mínimo para efeito de desoneração fiscal. Por fim, o adquirente de mercadorias entrepostadas é aquele que adquire mercadorias que foram importadas e estão depositadas no entreposto aduaneiro ou em feira, congresso, mostra ou evento semelhante, com a suspensão do pagamento do imposto e sob controle fiscal (artigos 356 e 357 do Decreto no $4.543 / 02)$.

De acordo com o art. 32 do Decreto-Lei no 37/66, são responsáveis pelo imposto de importação o transportador, quando transportar mercadoria procedente do exterior ou sob controle aduaneiro, inclusive em percurso interno; e, o depositário, assim considerada qualquer pessoa incumbida da custódia de mercadoria sob controle aduaneiro. $\mathrm{O}$ parágrafo único desse artigo traz os responsáveis solidários: o adquirente ou cessionário de mercadoria beneficiada com isenção ou redução do imposto; o representante, no País, do transportador estrangeiro; o adquirente de mercadoria de procedência estrangeira, no caso de importação realizada por sua conta e ordem, por intermédio de pessoa jurídica importadora; e, o encomendante predeterminado que adquire mercadoria de procedência estrangeira de pessoa jurídica importadora.

O critério quantitativo possibilita a precisão exata da quantia devida a título de tributo. É explicitado pela conjugação da base de cálculo com a alíquota. $\mathrm{O}$ imposto de importação é calculado pela aplicação das alíquotas previstas na Tarifa Aduaneira sobre a base de cálculo, de acordo com o Decreto-Lei no 37/66.

A base de cálculo é, conforme Maria Helena Diniz, "a medida padrão ou grandeza econômica adotada pela lei tributária que indica o modo de apuração do valor da prestação pecuniária a ser arrecadada" (apud CÓDIGO TRIBUTÁRIO NACIONAL: comentado e anotado, 2003, p. 52). São três as formas legais, indicadas no art. 20 do CTN, para caracterizar a base de cálculo:

a) a unidade de medida adotada pela lei tributária quando a alíquota for específica. A lei ordinária estabelece que a base de cálculo do imposto nesse caso é a quantidade de mercadoria, expressa na unidade de medida indicada na tarifa, v.g., quilos, litros, metros, volume, unidades etc;

b) o preço normal que o produto ou seu similar alcançaria, ao tempo da importação, em uma venda em condições de livre concorrência para a entrega no porto ou 
lugar de entrada do produto no país quando a alíquota for "ad valorem". Esse valor geralmente consta na fatura comercial do lugar da expedição da mercadoria, acrescentandose ao custo, as despesas de frete e seguro, até a entrega no porto ou local de destino no Brasil (BALEEIRO, 1985, p. 132), mas pode ser desconsiderado se houver motivos para dúvidas quanto à exatidão desse valor. $\mathrm{O}$ art. 2으, II, do Decreto-Lei $\mathrm{n}$ ㅇ 37/66 preceitua que, quando a alíquota for "ad valorem", a base de cálculo é o valor aduaneiro apurado segundo as normas do art.7ㅇ do Acordo Geral sobre Tarifas Aduaneiras e Comércio - GATT; e,

c) o preço da arrematação, quando se trata de produto apreendido ou abandonado levado a leilão.

As alíquotas podem classificar-se, consoante Leo Krakowiak e Ricardo Krakowiak (apud MELO, 2003, p. 61), como gerais, convencionais ou diferenciais: as gerais são as previstas na Tarifa Externa Comum e aplicáveis às importações em geral; convencionais são as objeto de acordos internacionais, bilaterais ou multilaterais, prevalecendo sobre as gerais; e diferenciais, em percentual superior às gerais, visam à retaliação aduaneira.

O Código Tributário Nacional menciona, em seu art. 20, a classificação das alíquotas em específica (quantia fixa em dinheiro referente a uma unidade de medida) e ad valorem (determinado percentual a ser aplicado à base de cálculo, que varia de produto para produto). Segundo Edivaldo Ravenna Picazo (apud CÓDIGO TRIBUTÁRIO NACIONAL: comentado e anotado, 2003, p. 54), as alíquotas específicas encontram-se em desuso. As alíquotas ad valorem estão previstas na Tarifa Externa Comum (TEC), instituída pelo Tratado de Assunção (Decreto Legislativo no 350/91) e devem ser adotadas pelos 04 Estados membros do MERCOSUL - Mercado Comum do Sul - (Brasil, Argentina, Paraguai e Uruguai). Com referência aos produtos oriundos de terceiros países, de acordo com José Eduardo Soares de Melo (2003, p. 61), o Brasil assumiu o compromisso junto ao GATT de aplicar determinadas alíquotas.

\section{Critério temporal nos tribunais}

Em consonância com o art. 19 do CTN, o Decreto-Lei no 37/66, em seu artigo 1으, estabelece que o imposto de importação incide sobre mercadoria estrangeira e tem como fato gerador a sua entrada no território nacional. Contudo, em seu artigo 23 , dispõe que, em se tratando de mercadoria despachada para consumo, considera-se como ocorrido o fato 
gerador na data do registro, na repartição aduaneira competente, da declaração feita para o desembaraço da mercadoria.

Em face disso, no que atine ao momento da ocorrência do fato gerador, dúvidas poderiam surgir sobre se o fato gerador seria a entrada da mercadoria no território nacional ou a data do registro da declaração de importação porquanto entre tais datas poderiam decorrer vários dias, sendo que nesse período haveria a possibilidade de ser a alíquota do imposto de importação majorada, prejudicando o sujeito passivo.

Os Tribunais vêm decidindo reiteradamente que, no caso de importação de mercadoria despachada para consumo, o fato gerador, para o imposto de importação, consuma-se na data do registro da declaração de importação, inexistindo incompatibilidade entre o art. 23 do Decreto-lei 27/66 e o art. 19 do CTN, sendo irrelevante o regime fiscal vigente na data da emissão da guia de importação, ou quando do desembarque da mercadoria.

O STF proclamou inexistir incompatibilidade do art. 19 do CTN com os arts. 23 e 24 do D.L. 37/66 e, no julgamento da ADI (ação direta de inconstitucionalidade) no 1293-DF, manifestou-se, in verbis:

O imposto de importação tem como fato gerador a entrada de produtos estrangeiros no território (CTN-66, art. 19). Tratando-se de mercadoria despachada para consumo, considera-se ocorrido o fato gerador na data do registro, na repartição competente, da declaração apresentada pelo importador (DEL-37/66), art. $23 \mathrm{c} / \mathrm{c}$ art. 44), sendo irrelevante para esse efeito específico, a data da celebração do contrato de compra e venda ou a do embarque ou a do ingresso no país de mercadoria importada.

Para o STJ, o desembaraço aduaneiro, por completar a importação, representa, para efeitos fiscais, a entrada no território da mercadoria, inclusive quando se trata de mercadoria de bens de capital/de produção porque entende que o termo "mercadoria para consumo" tem sentido amplo, conforme as seguintes ementas:

IMPORTAÇÃO. FATO GERADOR. COMPATIBILIDADE DO ART. 23 DO DECRETO-LEI N. 37/66 COM O ART. 19 DO CTN. DISSÍDIO PRETORIANO. SÚMULA N. 83/STJ. PRECEDENTES. [...] 3. O STJ já pacificou o entendimento de que inexiste incompatibilidade entre o art. 19 do Código Tributário Nacional e o art. 23, parágrafo único, do Decreto-Lei n. 37/66, visto que o desembaraço aduaneiro completa a importação e, conseqüentemente, representa, para efeitos fiscais, a entrada no território nacional da mercadoria. [...] (STJ - RESP 184861, Processo 
199800584900/RJ, Órgão Julgador SEGUNDA TURMA, DJ DATA 16/05/2005, p. 273, Relator JOÃO OTÁVIO DE NORONHA).

TRIBUTÁRIO. IMPOSTO DE IMPORTAÇÃO. BENS DE CAPITAL. FATO GERADOR. REGISTRO. REPARTIÇÃOO ADUANEIRA. DECLARAÇÃO DE IMPORTAÇÃO. "MERCADORIA PARA CONSUMO". INTERPRETAÇÃO GENÉRICA. DECRETO-LEI № 37/66. I - Esta Corte já possui entendimento assentado no sentido de que o fato gerador do imposto de importação ocorre na data do registro, na repartição aduaneira, da declaração de importação, consubstanciado pelo desembaraço aduaneiro, não havendo que se falar em incompatibilidade entre o art. 23 do Decreto-lei no 37/66 e o art. 19 do CTN. Precedentes: REsp no 157.162/SP, Rel. Min. CASTRO MEIRA, DJ de 01/08/05 e REsp no 184.861/RJ, Rel. Min. JOÃO OTÁVIO DE NORONHA, DJ de 16/05/05. II - O argumento no sentido de que, no caso de bens de capital, o fato gerador do imposto de importação se realiza com a entrada do produto no território nacional não se sustenta, eis que o termo "mercadoria para consumo", previsto no Decreto-lei no 37/66 tem sentido genérico, aplicando-se inclusive aos bens de produção. Precedente: EDcl no REsp no 313.117/PE, Relatora Ministra DENISE ARRUDA, DJ de 10/05/04. [...] (STJ - AGRESP 412220, Processo 200200161906/RS, Órgão Julgador PRIMEIRA TURMA, DJ DATA 19/12/2005, p. 211, Relator FRANCISCO FALCÃO).

Por outro lado, o STJ também reconhece que o imposto de importação tem como fato gerador a entrada da mercadoria de procedência estrangeira no território nacional, sendo esta regra a que prevalece na importação de bens de capital, o que vai de encontro com o entendimento acima demonstrado:

TRIBUTÁRIO. IMPOSTO DE IMPORTAÇÃO. FATO GERADOR. COMPATIBILIDADE DO ARTIGO 19 DO CÓDIGO TRIBUTÁRIO NACIONAL COM O ARTIGO 23 DO DECRETOLEI № 37/66. BENS DE CAPITAL. FATO GERADOR. MOMENTO DA OCORRÊNCIA. ENTRADA. TERRITÓRIO NACIONAL. 1. A regra geral prevista nos artigos 19 do Código Tributário Nacional e 10 do Decreto-Lei no 37/66 dispõem que o imposto de importação tem como fato gerador a entrada da mercadoria de procedência estrangeira no território nacional. 2. Quando se tratar de mercadoria destinada ao consumo considera-se ocorrido o fato gerador do imposto de importação a data da do registro na repartição aduaneira da declaração feita para fins de desembaraço aduaneiro, consoante o disposto no artigo 23 do Decreto-Lei no 37/66, o qual é compatível com o artigo 19 do Código Tributário Nacional. Precedentes. 3. Prevalece a regra geral insculpida no artigo 19 do Código Tributário Nacional na importação de bens de capital - o fato gerador do imposto de importação ocorre na entrada dos produtos estrangeiros no território nacional. 4. Recurso especial improvido (STJ - RESP 328835, Processo 200100697108/SC, Órgão Julgador SEGUNDA TURMA, DJ DATA 14/11/2005, p. 236, Relator CASTRO MEIRA).

Diante disso, verifica-se que o STJ, muito embora afirme que o fato gerador do imposto de importação é a data da entrada da mercadoria no território nacional, considera que, quando se trata de mercadoria para consumo (em sentido amplo), para fins fiscais, a tal 
entrada é representada pela declaração de importação e ora decide que isto se aplica aos bens de capital (decisão da 1aㅡ Turma), ora sustenta que não (decisão da 2ạ Turma).

O TRF da 4a Região caminha na mesma direção, entende que o fato gerador do imposto de importação ocorre com a declaração da importação e não com a entrada física da mercadoria no território nacional, sendo irrelevantes as datas de embarque da mercadoria, de celebração do contrato de compra e venda e do momento do ingresso físico dos bens em território nacional:

TRIBUTÁRIO. IMPORTAÇÃO. TRIBUTOS. OCORRÊNCIA DO FATO GERADOR. DESEMBARAÇO ADUANEIRO. TAXA DE CÂMBIO. LEGALIDADE. 1. A legislação tributária aplicável à operação de importação é aquela vigente à época do fato gerador, nos termos do art. 105, do CTN, e art. 150, III, a, da Constituição Federal. 2. O fato gerador do Imposto de Importação ocorre por ocasião do registro da Declaração de Importação, momento que se dá o desembaraço aduaneiro da mercadoria, e não com a simples entrada física desta no território nacional. 0 desembaraço aduaneiro completa a importação e, conseqüentemente, representa, para efeitos fiscais, a entrada no território nacional da mercadoria. 3.0 art. 106, da Lei no $8.981 / 95$, autorizou o Poder Executivo a alterar a forma de fixação e a periodicidade da taxa de câmbio, não havendo que se falar na existência de direito adquirido à utilização de determinada taxa de câmbio fixa. Ademais, a variação do câmbio da moeda estrangeira não representa majoração do tributo, nem alteração da base de cálculo ou da alíquota. Ao contrário, a base de cálculo será simplesmente o resultado aritmético da conversão do valor expresso em moeda estrangeira com a taxa vigente. Portanto, não agiu com excesso de poder o Executivo ao alterar a taxa de câmbio, submetendo-a à livre flutuação do mercado, em coerência com a política econômica global adotada à época (TRIBUNAL QUARTA REGIÃO, MAS, Processo 200004010444968/PR, Órgão Julgador PRIMEIRA TURMA, DJU DATA 26/04/2006, p. 848, Relatora VIVIAN JOSETE PANTALEÃO CAMINHA).

TRIBUTÁRIO. IMPOSTO DE IMPORTAÇÃO. BENEFÍCIO PARA OS PAÍSES DO MERCOSUL. MAJORAÇÃO DA ALÍQUOTA. FATO GERADOR. REGISTRO DA DECLARAÇÃO DE IMPORTAÇÃO. A Portaria no 115, de 28 de março de 1995, que beneficia a importação entre os países do Mercosul não é extensível aos produtos originários de terceiros países. A majoração de alíquota de imposto de importação por Portaria Interministerial atende à necessidade de controle da atividade econômica. O imposto de importação tem por alíquota aquela vigente no momento de ocorrência de seu fato gerador, que no caso de mercadoria pronta para consumo, é o registro da declaração de importação na repartição aduaneira. Irrelevante as datas de embarque da mercadoria, de celebração do contrato de compra e venda e do momento do ingresso físico dos bens em território nacional. Havendo julgamento simultâneo dos feitos, desacolhendo-se, no mérito, a pretensão do autor, na ação principal, deve a ação cautelar ser julgada igualmente improcedente face a ausência de fumus boni iuris. Apelação improvida e remessa oficial provida (TRIBUNAL - QUARTA REGIÃO, AC, Processo 199804010338540/PR, Órgão Julgador SEGUNDA TURMA, DJU DATA 26/07/2000, p. 75/76, Relator JOÃO PEDRO GEBRAN NETO). 
Assim, constata-se que o entendimento desses tribunais está, de certa forma, em consonância. Contudo, data vênia, não parece ser essa a melhor interpretação da lei tributária. Hugo de Brito Machado (2006, p. 318) leciona que a entrada do produto estrangeiro no território nacional constitui a ocorrência do fato gerador e o desembaraço aduaneiro a forma pela qual tal ocorrência se exterioriza ou é documentada e, "apenas por questão de ordem prática, para fins de determinação da taxa de câmbio a ser utilizada na conversão do valor das mercadorias importadas para a moeda nacional, considera-se a data da declaração para o desembaraço aduaneiro".

O mesmo doutrinador (MACHADO, 2006, p. 319) afirma, ainda, que a entrada da mercadoria no território nacional não pode ser vista como fato isolado, de maneira que se o sujeito passivo obtém a guia de importação (ou forma equivalente de autorização da importação) ou efetua o contrato de câmbio e efetiva a aquisição do bem no exterior, tem direito a que a importação se complete no regime jurídico então vigente (art. 150, III, "a" c/c o art. 5ㅇ, XXXVI de CF). Isso porque, se assim não fosse, a importação como atividade empresarial seria inviável uma vez que "o governo poderia levar à ruína qualquer importador com um simples ato de elevação de alíquota do imposto de importação, o que efetivamente não é compatível com o Estado de Direito que assegura a livre iniciativa econômica" (MACHADO, 2006, p. 319).

Para Edivaldo Ravenna Picazo, o momento da ocorrência do fato gerador do imposto de importação apresenta-se em destaque à vista do princípio da não surpresa e, ao examinar a decisão do STF acima exposta aduz que

este silogismo tem levado muitos empresários a sofrer irrecuperáveis prejuízos financeiros em decorrência de aumentos inesperados e muitas vezes abusivos, de alíquotas, exatamente no momento em que mercadorias importadas estariam sendo descarregadas em áreas aduaneiras, sem que ainda se estivesse expedida a declaração de importação. A melhor solução não nos parece aquela aplicada pela Excelsa Corte, pois desconsidera o princípio da não surpresa. De acordo com nosso entendimento dever-se-ia optar por uma interpretação teleológica e extensiva do dispositivo, permitindo, sem prejuízo da legalidade, que o importador que já houvesse concluído os atos preparatórios para o recebimento da mercadoria, não sofresse os efeitos da mudança extraordinária de alíquotas. Isso daria a devida segurança jurídica a qualquer negócio internacional, numa área de mercado na qual se espera plena estabilidade e regras claras de transição (apud CóDIGO TRIBUTÁRIO NACIONAL: comentado e anotado, 2003, p. 51-52). 
Sabe-se que é facultado ao Poder Executivo alterar as alíquotas do imposto de importação e aplicá-las de imediato ao sujeito passivo porque o objetivo maior é proteger o mercado interno brasileiro. No entanto, deve-se observar o critério temporal desse imposto fixado em lei.

Ora, o entendimento dos tribunais acima mencionados fere, data venia, o ordenamento jurídico brasileiro porque está expresso tanto no Código Tributário Nacional (art. 1ㅇ) como no Decreto-Lei no 37/66 (art. 1ㅇ) que o fato gerador do imposto de importação é a data da entrada da mercadoria no território nacional. Além disso, o artigo 150, III, "a", da Magna Carta brasileira preceitua que, sem prejuízo de outras garantias asseguradas ao contribuinte, é vedado à União, aos Estados, ao Distrito Federal e aos Municípios cobrar tributos em relação a fatos geradores ocorridos antes do início da vigência da lei que os houver instituído ou aumentado.

Sendo assim, o imposto de importação deve ser sempre calculado de acordo com as regras vigentes no momento da entrada da mercadoria no território nacional. Não é porque a mercadoria se destina ao consumo que deveria receber tratamento diferenciado. $\mathrm{O}$ artigo 23 do Decreto-Lei no $37 / 66$ revela-se, portanto, imbuído de ilegalidade e inconstitucionalidade ao considerar como ocorrido o fato gerador na data da declaração de importação, quando se tratar de mercadorias destinadas ao consumo.

\section{Conclusão}

O fim precípuo de imposto de importação é proteger a indústria nacional e o secundário é arrecadar recursos financeiros aos tesouros públicos. Em vista disso, é livre do princípio da anterioridade e não precisa observar o prazo de 90 dias da publicação da lei (art. 150, II, c e $\S 1$ 으, CF). Faculta-se, ainda, ao Poder Executivo alterar a alíquota do imposto de importação (art. 153, § 1ㅇ, CF), sem depender das reformulações legislativas, cujos procedimentos são normalmente morosos.

A regra matriz desse imposto pode ser formulada da forma que segue. Hipótese Tributária - critério material: importar produto estrangeiro; critério espacial: território nacional até o limite da zona contígua (24 milhas marítimas); critério temporal: momento da entrada da mercadoria no território nacional. 
Relação Jurídica Tributária - critério pessoal: o sujeito ativo é a União e o sujeito passivo é o importador ou quem a ele a lei equiparar; critério quantitativo: a base de cálculo, dependendo do caso, pode ser a unidade de medida adotada pela lei tributária, o preço normal do produto importado ou o preço da arrematação do produto importado e leiloado; a alíquota é a fixada na tabela e pode ser específica, ad valorem ou convencional (também depende de cada caso em concreto).

Quanto ao critério temporal, merece ser o entendimento dos tribunais modificado no sentido de que o momento do fato gerador do imposto de importação deve ser considerado como a data da entrada do produto estrangeiro no território nacional, inclusive no que diz respeito às mercadorias destinadas ao consumo, devendo ser declara a ilegalidade e inconstitucionalidade do artigo 23 c/c o artigo 44 do Decreto-Lei no 37/66.

Isso porque, a entrada do produto estrangeiro no território nacional constitui o momento da realização do fato gerador do imposto de importação e o desembaraço aduaneiro apenas a forma pela qual tal ocorrência se exterioriza ou é documentada, razão pela qual deve ser aplicada a alíquota vigente ao tempo da entrada física da mercadoria no território nacional, sob pena de ofensa aos artigos 19 do CTN e 150, III, "a" c/c o art. 5으, XXXVI da CF.

\section{Referências}

BALEEIRO, Aliomar. Direito Tributário Brasileiro. 10. ed. Rio de Janeiro: Forense, 1985.

CARVALHO, Paulo de Barros. Curso de Direito Tributário. 17. ed. São Paulo: Saraiva, 2005.

CHIMENTI, Ricardo Cunha. Direito Tributário. 8. ed. São Paulo: Saraiva, 2005.

CÓDIGO Tributário Nacional: lei 5.172, de 25 de outubro de 1966: comentado e anotado. Coordenado por Volney Zamenhof de Oliveira Silva. 3. ed. Campinas: CS Edições, 2003.

MACHADO, Hugo de Brito. Curso de Direito Tributário. 27. ed. rev. atual. e ampl. São Paulo: Malheiros, 2006.

MARTINS, Ives Gandra da Silva. Questões Atuais de Direito Tributário. Belo Horizonte: Del Rey, 1999. 
MELO, José Eduardo Soares de. A Importação no Direito Tributário: impostos, taxas e contribuições. São Paulo: RT, 2003. 